\title{
Three coordination compounds based on benzene tetracarboxylate ligand: syntheses, structures, thermal behaviors and luminescence properties
}

\author{
YUNLONG WU, CHANGKUN XIA, JUN QIAND and JIMIN XIE* \\ School of Chemistry and Chemical Engineering, Jiangsu University, Zhenjiang 212013, \\ People's Republic of China \\ E-mail: xiejm391@ sohu.com
}

MS received 29 March 2017; revised 18 May 2017; accepted 29 May 2017

\begin{abstract}
Using 1,2,3,5-benzenetetracarboxylic acid and different pyridyl ligands, three metalorganic coordination compounds, $\left[\mathrm{Co}\left(\mathrm{H}_{3}\right.\right.$ btec $)(1,10-$ phen $\left.)\left(\mathrm{H}_{2} \mathrm{O}\right)_{3}\right][\mathrm{OH}] \cdot 2 \mathrm{H}_{2} \mathrm{O}(\mathbf{1})$, [ $\mathrm{Co}_{2}$ (btec) $\left(2,2^{\prime} \text { '-bipy }\right)_{2}$ $\left.\left(\mathrm{H}_{2} \mathrm{O}\right)\right] \cdot \mathrm{H}_{2} \mathrm{O}(\mathbf{2}),\left\{\left[\mathrm{Co}_{1.5}\left(\mathrm{H}_{2}\right.\right.\right.$ btec $)\left(4,4^{\prime}\right.$-bipy $\left.)\left(\mathrm{H}_{2} \mathrm{O}\right)_{2}\right]\left[\mathrm{Co}_{0.5}\left(4,4^{\prime}\right.\right.$-bipy $\left.\left.)-\left(\mathrm{H}_{2} \mathrm{O}\right)_{4}\right][\mathrm{OH}]_{2}\right\} \cdot 2 \mathrm{H}_{2} \mathrm{O}(\mathbf{3}),\left(\mathrm{H}_{4}\right.$ btec $=$ 1, 2, 3, 5-benzenetetracarboxylic acid, 1,10-phen =1,10-phenanthroline, 2,2'-bipy =2,2' -bipyridine, 4,4'-bipy $=4,4^{\prime}$-bipyridine) were synthesized by hydrothermal method and characterized by elemental analysis, infrared spectroscopy, and single-crystal X-ray diffraction analysis. X-ray crystallographic studies reveal that $\mathbf{1}$ is a discrete 0D coordination compound, while $\mathbf{2}$ and $\mathbf{3}$ possess similar 2D network structures, which show a sql network with the point symbol of $(4,4)$. Thermal analysis indicates that compounds $\mathbf{1}$ and $\mathbf{2}$ begin to collapse after $350^{\circ} \mathrm{C}$. Further, the UV-Vis DRS spectra and solid-state luminescent properties of $\mathbf{1}-\mathbf{3}$ have also been studied.
\end{abstract}

Keywords. Hydrothermal synthesis; multicarboxylate ligand; coordination polymer; luminescence; thermal behavior.

\section{Introduction}

Owing to the fascinating topological structures and potential application in magnetism, catalysis and luminescence, considerable attention has been focused on the construction of coordination compounds. ${ }^{1-5}$ Many efforts in this field are focused on the rational design and synthesis of functional molecules and materials. ${ }^{6-9}$ Recently, several synthetic strategies have been successfully applied in the construction of functional coordination compounds, including the use of metal-involved building blocks and multi-functional ligands. ${ }^{10-12}$ It is well-known that the multi-topic organic ligands are good candidates as multi-functional ligands to enrich the structural diversity of coordination compounds, from discrete molecules to multidimensional assemblies. ${ }^{13-18}$ Among the numerous multi-topic organic ligands, benzene polycarboxylic acids (BPCAs), have witnessed the most important development of coordination polymers owing to their rich coordination modes. ${ }^{19-22}$ For example, tritopic 1,3,5-Benzene-tricarboxylic acid ${ }^{23-31}$ $\left(\mathrm{H}_{3} \mathrm{BTC}\right.$, also known as trimesic acid) and 1,2,4,5Benzenetetracarboxylic acid ${ }^{32-35}$ (BTEC) with three and four carboxylic groups, respectively, have been widely introduced into the fabrication of numerous coordination compounds with various structures and different properties. However, the use of 1,2,3,5-Benzenetetracarboxylic acid, which also contains four carboxylic acid groups, in the construction of coordination compounds was explored to a lesser extent. In the last one year, we have reported several new coordination compounds based on 1,2,3,5-Benzenetetracarboxylic acid. ${ }^{36-38}$ Compared with N-containing ligands, 4carboxyl groups from 1,2,3,5-Benzenetetracarboxylic acid can not only coordinate with metal centers via the coordination bonds, but also act hydrogen bonding donor and acceptor. In addition, the completely or partially deprotonated multicarboxylate ligands from 1,2,3,5-Benzenetetracarboxylic acid can adopt various coordination modes with metal centers, which will give

\footnotetext{
*For correspondence
}

Electronic supplementary material: The online version of this article (doi:10.1007/s12039-017-1319-x) contains supplementary material, which is available to authorized users. 
numerous possibilities to the final structures of coordination compounds.

From the synthetic point of view, several critical factors, such as metal/ligand ratio, solvent polarity, kinds of the organic ligands, and the counter ions, have more influence on the structures and properties of coordination compounds. For example, the participation of different types of ligands during the synthetic process is a useful approach to the structural diversity of coordination compounds. Therefore, the combination of 1,2,3,5-Benzenetetracarboxylic acid $\left(\mathrm{H}_{4}\right.$ btec $)$ with other kind of ligands may also increase the variety of structures and topologies. In this regard, $\mathrm{H}_{4}$ btec-based coordination compounds possibly possessing distinctive architectures and applicable functions can be achieved by using the N-containing auxiliary ligands, such as 2,2'-bipyridine (2,2'-bipy), 1,10phenanthroline (1,10-phen), and 4,4'-bipyridine (4,4'bipy) (Scheme 1).

Herein, we report the hydrothermal synthesis of three coordination compounds based on 1,2,3,5-Benzenetetracarboxylic acid and three different $\mathrm{N}$-containing auxiliary ligands (1,10-phen, 2,2'-bipy, and 4,4'-bipy). All three compounds $\left[\mathrm{Co}\left(\mathrm{H}_{3}\right.\right.$ btec $)(1,10$-phen $\left.)\left(\mathrm{H}_{2} \mathrm{O}\right)_{2}\right]$ $[\mathrm{OH}] \cdot 3 \mathrm{H}_{2} \mathrm{O}(\mathbf{1}),\left[\mathrm{Co}_{2}\right.$ (btec)(2,2'-bipy) $\left.{ }_{2}\left(\mathrm{H}_{2} \mathrm{O}\right)\right] \cdot \mathrm{H}_{2} \mathrm{O}$ (2), and $\left\{\left[\mathrm{Co}_{1.5}\left(\mathrm{H}_{2}\right.\right.\right.$ btec $)(4,4$ '-bipy $\left.)\left(\mathrm{H}_{2} \mathrm{O}\right)_{2}\right]\left[\mathrm{Co}_{0.5}(4,4\right.$ 'bipy) $\left.\left.\left(\mathrm{H}_{2} \mathrm{O}\right)_{4}\right][\mathrm{OH}]_{2}\right\} \cdot 2 \mathrm{H}_{2} \mathrm{O}(3)$ have been characterized by elemental analysis, infrared spectroscopy, and single-crystal X-ray diffraction analysis. X-ray crystallographic studies reveal that $\mathbf{1}$ is a discrete OD coordination compound, while $\mathbf{2}$ and $\mathbf{3}$ exhibit the 2D network structures with a sql topology. Thermogravimetric analysis indicates that the main structures of the compounds 1 and 2 begin to collapse after $350^{\circ} \mathrm{C}$. Moreover, the thermal properties, UV-Vis analysis and photoluminescent properties of compounds 1-3 have been studied.

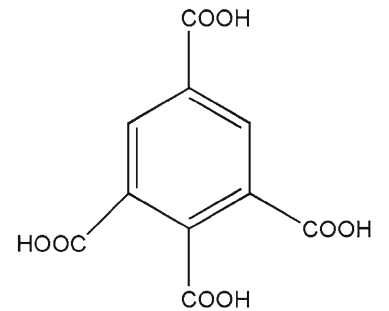

$\mathrm{H}_{4}$ btec

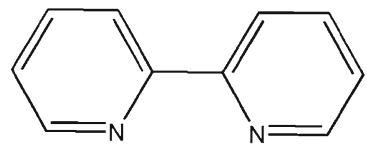

2,2'-bipy

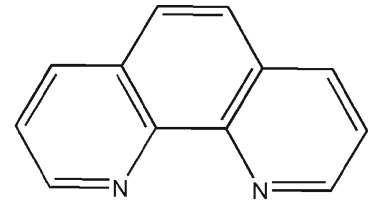

1,10-phen

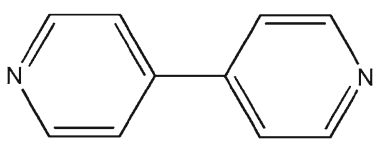

4,4'-bipy
Scheme 1. Structure of $\mathrm{H}_{4}$ btec and bipyridyl ligands.

\section{Experimental}

\subsection{Materials and physical measurements}

All the chemicals were commercially available and used without further purification. Elemental analyses for C, $\mathrm{H}$ and $\mathrm{N}$ were performed with a Perkin Elmer 240C system. Infrared spectra were recorded in the range of $400-4000 \mathrm{~cm}^{-1}$ with a Nicolet Nexus 470 spectrometer (Germany) with samples as $\mathrm{KBr}$ disks. The powder X-ray study was recorded on a XD-3 diffractometer equipped with a sealed tube $\mathrm{Cu} \mathrm{K} \alpha \mathrm{X}$-ray radiation (generator power settings: $35 \mathrm{kV}$ and $20 \mathrm{~mA}$ ) and a DTex Ultra detector using the parallel beam geometry $\left(5^{\circ}\right.$ primary and $80^{\circ}$ terminated, $3^{\circ}$ divergence slit with $10 \mathrm{~mm}$ height limit slit). Thermogravimetric analysis (TGA) measurements were carried out with a Perkin Elmer Pyis 1 system under nitrogen purge at a heating rate of $10^{\circ} \mathrm{C} \mathrm{min}-1$. UltravioletVisible spectra (UV-Vis) were recorded on a Varian Cary 5000 Spectrophotometer, corrected by $\mathrm{BaSO}_{4}$. The fluorescence measurements were performed on ground powder samples at room temperature using an Edinburgh analytical instrument FLS920.

\subsection{Preparation of $\left[\mathrm{Co}\left(\mathrm{H}_{3}\right.\right.$ btec $)($ phen $\left.)\left(\mathrm{H}_{2} \mathrm{O}\right)_{3}\right][\mathrm{OH}]$ - $2 \mathrm{H}_{2} \mathrm{O}(1)$}

A mixture of $\mathrm{Co}\left(\mathrm{NO}_{3}\right)_{2} \cdot 6 \mathrm{H}_{2} \mathrm{O}(0.0292 \mathrm{~g}, 0.1 \mathrm{mmol}), \mathrm{H}_{4} \mathrm{btec}$ (0.0127 g, $0.05 \mathrm{mmol}), 1,10$-phen $(0.018 \mathrm{~g}, 0.1 \mathrm{mmol}), \mathrm{H}_{2} \mathrm{O}$ $(3 \mathrm{~mL})$ was placed in a $10 \mathrm{~mL}$ vial, and the $\mathrm{pH}$ value was adjusted to 4.0 by addition of $1 \mathrm{M} \mathrm{NaOH}$ solution. The vial was sealed in a Teflon-lined stainless steel vessel, heated at $120^{\circ} \mathrm{C}$ for three days, and then it was gradually cooled to room temperature. The pink plate crystals were obtained in $68 \%$ yield. Elemental Anal. Calc. for $\mathrm{C}_{22} \mathrm{H}_{20} \mathrm{~N}_{2} \mathrm{O}_{14} \mathrm{Co}$ (595.34): C, 44.34; H, 3.36; N, 4.70\%; Found: C, 44.18; H, $3.41 ; \mathrm{N}, 4.69 \%$. IR (KBr pellet) $v / \mathrm{cm}^{-1}: 3486 \mathrm{w}, 3248 \mathrm{~m}$, 3012 w, 1722s, 1595s, 1431s, 1372s, 1205w, 1072w, 937w, $856 \mathrm{~m}, 824 \mathrm{~s}, 780 \mathrm{~m}, 683 \mathrm{~m}, 651 \mathrm{w}, 624 \mathrm{w}, 490 \mathrm{w}, 457 \mathrm{w}$.

\subsection{Preparation of $\left[\mathrm{Co}_{2}(\right.$ btec $\left.)\left(2,2^{\prime} \text {-bipy }\right)_{2}\left(\mathrm{H}_{2} \mathrm{O}\right)\right]$. $\mathrm{H}_{2} \mathrm{O}(2)$}

The preparation of $\mathbf{2}$ was similar to that for compound $\mathbf{1}$, except that 2,2'-bipy $(0.0156 \mathrm{~g}, 0.1 \mathrm{mmol})$ was used instead of 1,10-phen and the $\mathrm{pH}$ value was adjusted to 5.0. The pink crystals were obtained in $65 \%$ yield. Elemental Anal. Calc. for $\mathrm{C}_{30} \mathrm{H}_{19} \mathrm{~N}_{4} \mathrm{O}_{10} \mathrm{Co}_{2}$ (713.35): C, 50.47; H, 2.66; N, 7.85\%; Found: C, 50.60; H, 2.65; N, 7.83\%. IR (KBr pellet) $\nu / \mathrm{cm}^{-1}$ : 3544 w, 2959w, 1629s, 1580s, 1475s, 1426s, 1340s, 1223m, $1081 \mathrm{~m}, 1032 \mathrm{~m}, 1001 \mathrm{w}, 946 \mathrm{~m}, 872 \mathrm{~m}, 816 \mathrm{~m}, 785 \mathrm{~m}, 743 \mathrm{~s}$, $620 \mathrm{~m}, 558 \mathrm{w}, 527 \mathrm{~m}$.

\subsection{Preparation of $\left\{\left[\mathrm{Co}_{1.5}\left(\mathrm{H}_{2}\right.\right.\right.$ btec $)\left(4,4^{\prime}\right.$-bipy $\left.)\left(\mathrm{H}_{2} \mathrm{O}\right)_{2}\right]$ $\left[\mathrm{Co}_{0.5}\left(4,4^{\prime}\right.\right.$-bipy)- $\left.\left.\left(\mathrm{H}_{2} \mathrm{O}\right)_{4}\right][\mathrm{OH}]_{2}\right\} \cdot 2 \mathrm{H}_{2} \mathrm{O}(\mathbf{3})$}

The preparation of $\mathbf{3}$ was similar to that for compound $\mathbf{1}$, except that 4,4'-bipy $(0.0156 \mathrm{~g}, 0.1 \mathrm{mmol})$ was used instead 
Table 1. Crystallographic data for coordination compounds 1-3.

\begin{tabular}{llll}
\hline Compounds & \multicolumn{2}{c}{$\mathbf{1}$} & \multicolumn{1}{c}{$\mathbf{3}$} \\
\hline Formula & $\mathrm{C}_{22} \mathrm{H}_{20} \mathrm{~N}_{2} \mathrm{O}_{14} \mathrm{Co} \mathrm{C}_{30} \mathrm{H}_{19} \mathrm{~N}_{4} \mathrm{O}_{10} \mathrm{Co}_{2}$ & $\mathrm{C}_{30} \mathrm{H}_{28} \mathrm{~N}_{4} \mathrm{O}_{18} \mathrm{Co}_{2}$ \\
Formula weight & 595.34 & 713.35 & 850.44 \\
$T(\mathrm{~K})$ & $293(2)$ & $293(2)$ & $293(2)$ \\
Crystal system & orthogonal & Monoclinic & Monoclinic \\
Space group & $P b c a$ & $P 21 / c$ & $C 2$ \\
$a(\AA)$ & $24.137(5)$ & $19.607(4)$ & $19.477(4)$ \\
$b(\AA)$ & $7.4424(15)$ & $9.806(2)$ & $11.397(2)$ \\
$c(\AA)$ & $26.882(5)$ & $14.521(3)$ & $15.884(3)$ \\
$\alpha\left({ }^{\circ}\right)$ & 90 & 90 & 90 \\
$\beta\left({ }^{\circ}\right)$ & 90 & $98.70(3)$ & $93.10(3)$ \\
$\gamma\left({ }^{\circ}\right)$ & 90 & 90 & 90 \\
$V\left(\AA^{3}\right)$ & $4829.0(17)$ & $2759.8(10)$ & $3520.8(12)$ \\
$Z$ & 8 & 4 & 4 \\
$D_{\text {calc }}\left(\mathrm{g} /\right.$ cm $\left.^{3}\right)$ & 1.61 & 1.714 & 1.566 \\
$M($ Mo $K \mathrm{a})\left(\mathrm{mm}{ }^{-1}\right)$ & 0.789 & 1.273 & 1.026 \\
$\theta$ Range $\left({ }^{\circ}\right)$ & $3.03-25.35$ & $3.14-25.35$ & $3.26-26.02$ \\
$F(000)$ & 2360 & 1440 & 1656 \\
Total reflections & 12746 & 11148 & 14218 \\
Unique reflections & 4374 & 5006 & 6647 \\
$R_{\text {int }}$ & 0.0680 & 0.0869 & 0.0503 \\
Goodness of fit & 1.154 & 1.159 & 0.954 \\
$\mathrm{R}_{1}, w \mathrm{R}_{2}[I>2 \sigma(I)]$ & $0.0749 / 0.1389$ & $0.0904 / 0.1445$ & $0.0422 / 0.0650$ \\
$\mathrm{R} 1, w \mathrm{R}_{2}($ all data $)$ & $0.0938 / 0.1482$ & $0.1363 / 0.1664$ & $0.0527 / 0.0684$ \\
$\Delta \rho_{\text {max }}, \Delta \rho_{\text {min }}\left(\mathrm{e} \cdot \AA^{-3}\right)$ & $0.523 /-0.611$ & $0.602 /-0.514$ & $0.409 /-0.471$ \\
\hline
\end{tabular}

of 1,10-phen. The block-like crystals of $\mathbf{3}$ (54\% yield) were obtained intermixed with a few colorless crystals. Elemental Anal. Calc. for $\mathrm{C}_{30} \mathrm{H}_{28} \mathrm{~N}_{4} \mathrm{O}_{18} \mathrm{Co}_{2}$ (850.44): C, 42.33; $\mathrm{H}$, 3.28; N, 6.58\%; Found: C, 42.61; H, 3.33; N, 6.55\%. IR (KBr pellet) $\nu / \mathrm{cm}^{-1}: 3159 \mathrm{~m}, 2458 \mathrm{w}, 1714 \mathrm{~s}, 1589 \mathrm{~m}, 1480 \mathrm{w}$, $1405 \mathrm{~m}, 1226 \mathrm{~s}, 1204 \mathrm{~s}, 1072 \mathrm{~m}, 976 \mathrm{~m}, 822 \mathrm{~m}, 805 \mathrm{~m}, 743 \mathrm{w}$, $650 \mathrm{~m}, 569 \mathrm{~m}, 523 \mathrm{w}$.

\subsection{Crystal structure determination}

Suitable single crystals of compounds $\mathbf{1}-\mathbf{3}$ were carefully selected under an optical microscope and glued to thin glass fibers. The diffraction data were collected on a Siemens SMART CCD diffractometer with graphite-monochromated Mo- $K a$ radiation $(\lambda=0.71073 \AA$ ) at $298 \mathrm{~K}$. An empirical absorption correction was applied using the SADABS program. ${ }^{39}$ The structures were solved by direct methods and refined by full-matrix least-squares methods on $F^{2}$ by using the SHELX-97 program package. ${ }^{40}$ All non-hydrogen atoms were refined anisotropically. Hydrogen atoms of btec phenyl ring and pyridyl ligands were generated geometrically. The crystallography details for the structures determination of compounds 1-3 are presented in Table 1 .

\section{Results and Discussion}

\subsection{Synthesis and characterization}

Attempts to obtain suitable crystals for X-ray diffraction analysis from the reaction of $\mathrm{H}_{4}$ btec and cobalt(II) metal salts with $\mathrm{N}$-containing auxiliary ligands under the solvent diffusion method failed due to quick precipitation. It is well known that hydrothermal or solvothermal synthesis can provide an efficient method for the crystallization of coordination compounds, ${ }^{10,41-43}$ and this strategy was adopted for the reaction of $\mathrm{H}_{4}$ btec and cobalt(II) metal salts in water with $\mathrm{NaOH}$ as base and pyridyl as auxiliary ligands. Structure difference in compounds 1-3 may be attributed to the different coordination modes of $\mathrm{H}_{4}$ btec ligand as well as different steric hindrance of bipyridyl ligands. Among these compounds, cobalt(II) ions show similar octahedral coordination geometry, while the $\mathrm{H}_{4}$ btec ligands exhibit three different coordination modes. The X-ray powder diffraction (XRPD) has also been applied to check the phase purity of the bulk samples in the solid state. For compounds $\mathbf{1}$ and $\mathbf{2}$, the measured XRD patterns closely matched the simulated patterns, which were generated from the results of single-crystal diffraction data, indicative of pure products (see Figures S1 and S2 in the Supplementary Information). When compared to the simulated patterns based on the single crystal data of compound $\mathbf{3}$, the experimental pattern was also in agreement with the calculated diffractogram (see Figure S3 in SI). The powder X-ray diffraction results were in good agreement with the simulated pattern from single $\mathrm{X}$-ray diffraction thus confirm pure phase. 


\subsection{Crystal structures}

3.2a Crystal structure of 1: Compound $\mathbf{1}$ crystallizes in the orthogonal system with Pbca space group. Singlecrystal $X$-ray diffraction analysis reveals that compound 1 consists of one crystallographically unique Co(II) cation, one $\mathrm{H}_{3}$ btec $^{-}$anion, one phen ligand, three coordinated water molecules, one $\mathrm{OH}^{-}$ion and two free water molecules (Figure S4 in SI).: In compound $\mathbf{1}$, each $\mathrm{Co}$ (II) cation shows a distorted octahedral geometry $\left[\mathrm{CoN}_{2} \mathrm{O}_{4}\right]$, which is surrounded by two nitrogen atoms from the chelating 1,10-phen ligand, one carboxylate oxygen atom from $\mathrm{H}_{3}$ btec $^{-}$ligand, and three oxygen atoms from coordinated water molecules (Figure 1). The $\mathrm{H}_{4}$ btec ligand here is partly deprotonated, which is in agreement with the IR data in which strong absorption peaks around $1720 \mathrm{~cm}^{-1}$ for $-\mathrm{COOH}$ are observed. The $\mathrm{H}_{3} \mathrm{btec}^{-}$ligand bridges one $\mathrm{Co}^{2+}$ ion with the $\mu_{1}$-coordination mode. The $\mathrm{Co}-\mathrm{N}$ bond length falls in the range of 2.115(4)-2.127(5) $\AA$, while the Co-O

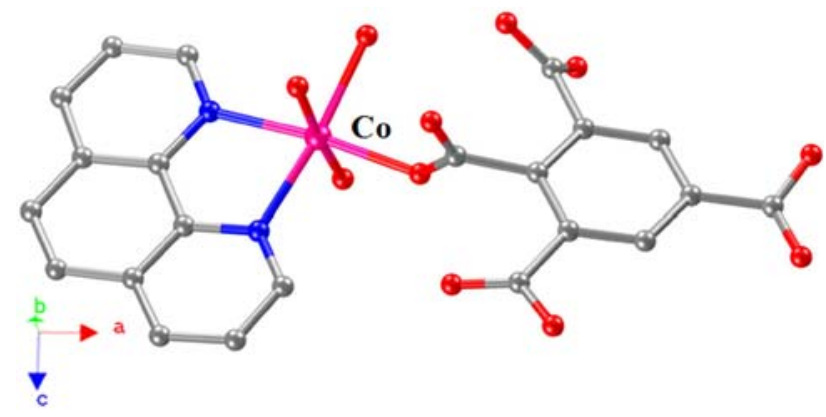

Figure 1. Structure of compound $\mathbf{1}$ ( $b$ axis). All hydrogen atoms are omitted for clarity. bond lengths vary from 2.097(4)-2.127(4) A. The packing structure of compound $\mathbf{1}$ is displayed in Figure S5 (see Supplememntary Information). Moreover, the 0D discrete molecules are further constructed into threedimensional supramolecular framework via hydrogen bonding interactions (Figure S6 in SI).

\section{2b Crystal structure of 2: Single-crystal X-ray struc-} tural analysis reveals that compound $\mathbf{2}$ crystallizes in the monoclinic system with $P 2_{1} / c$ space group. The asymmetric unit of $\mathbf{2}$ consists of two crystallographically independent cobalt(II) ions, one btec ${ }^{4-}$ ligand, two 2,2'-bipy ligands, one coordinated water molecule and one free water molecule (Figure S7 in SI).: As shown in Figure 2, the Co ion in compound $\mathbf{2}$ adopts a distorted octahedral coordination geometry but has two different coordination environments: Col ion is coordinated by two nitrogen atoms from the chelating 2,2'-bipy ligand, four carboxylate oxygen atoms from two different $\mathrm{btec}^{4-}$ ligands, while Co2 ion is coordinated by two nitrogen atoms from the chelating 2,2'-bipy ligand, three carboxylate oxygen atoms from two different btec ${ }^{4-}$ ligands and one oxygen atom from coordinated water molecule. $\mathrm{H}_{4}$ btec ligand in compound $\mathbf{2}$ is fully deprotonated, which is in agreement with the IR data in which no strong absorption peaks around $1720 \mathrm{~cm}^{-1}$ for $-\mathrm{COOH}$ are observed. Each btec ${ }^{4-}$ ligand bridges seven $\mathrm{Co}^{2+}$ ion with the $\mu_{7}$-coordination mode. The $\mathrm{Co}-\mathrm{N}$ bond length is in the range of 2.090(6)-2.124(6) $\AA$, while the Co-O bond lengths vary from 2.003(6)-2.260(6) $\AA$.

Viewed from Figure $3 \mathrm{a}$, four Co atoms bridged by $\mu_{2}$ carboxylate groups from four different $b \mathrm{ec}^{4-}$ ligands form 4-membered rings. Such rings are then extended to

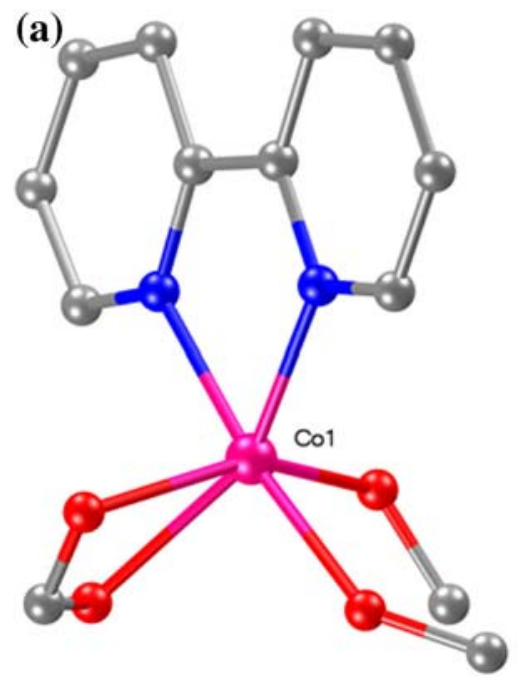

(b)

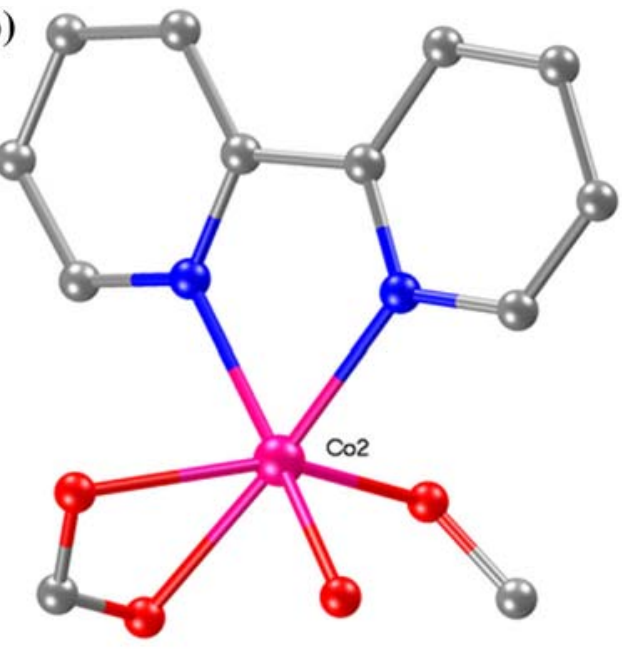

Figure 2. (a) Coordination environment of $\mathrm{Co} 1$ ion in compound 2. (b) Coordination environment of $\mathrm{Co} 2$ ion in compound $\mathbf{2}$. All hydrogen atoms are omitted for clarity. 
(a)

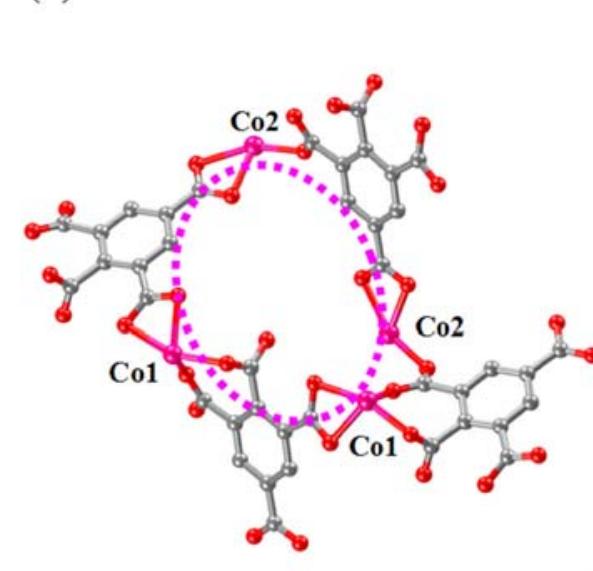

(b)

b)

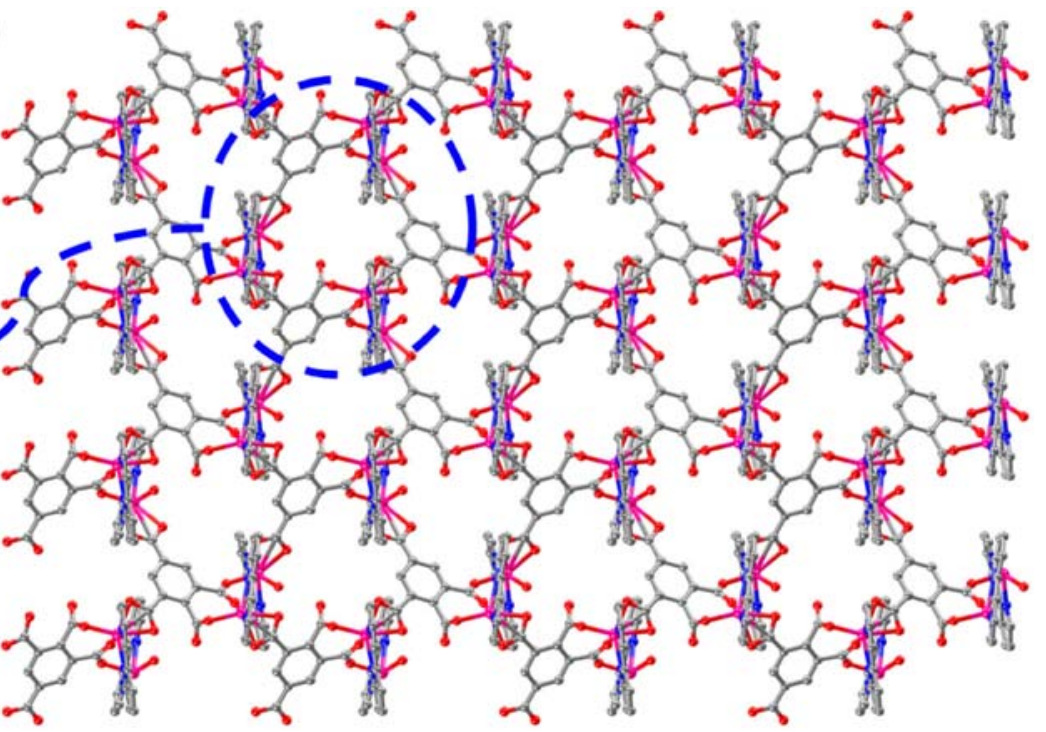

Figure 3. Packing structure of compound 2 ( $a$ axis). All hydrogen atoms are omitted for clarity.

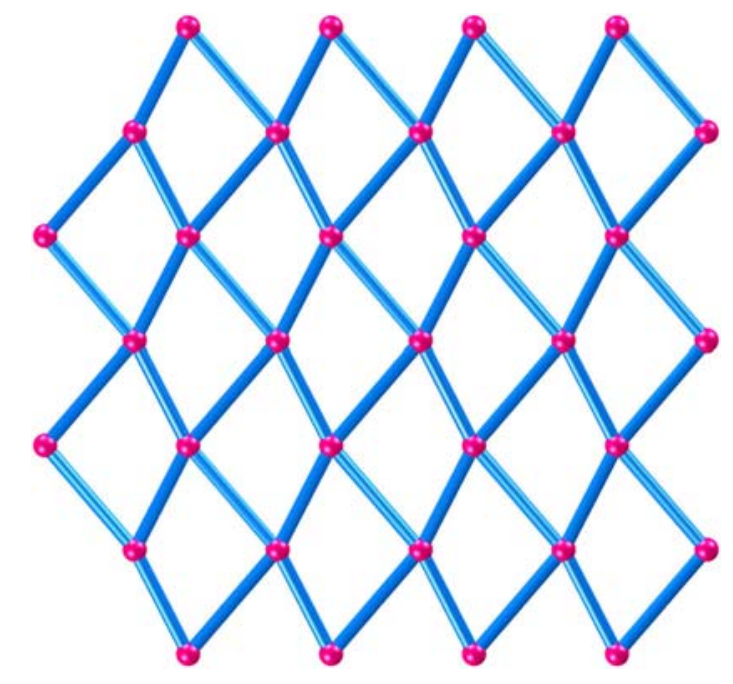

Figure 4. Topological structure of compound 2.

a 2D network structure through the 4-connected btec ${ }^{4-}$ ligands (Figure 3b). The network analysis based on TOPOS program reveals that compound $\mathbf{2}$ has a point symbol of $(4,4)$, which indicates a sql topology geometry (Figure 4).

\section{2c Crystal structure of 3 : The crystallographic anal-} ysis reveals that compound $\mathbf{3}$ crystallizes in the monoclinic system with C2 space group. The asymmetric unit consists of three crystallographically independent cobalt(II) ions, one $\mathrm{H}_{2}$ btec $^{2-}$, two 4,4'-bipy ligands, six coordinated water molecules, two $\mathrm{OH}^{-}$ions and two free water molecules (Figure S8 in SI).: As in compound 3 , the Co ions have two different coordination environments: Co1 ion shows a distorted octahedral geometry $\left[\mathrm{CoN}_{2} \mathrm{O}_{4}\right]$, which is surrounded by two nitrogen atoms from 4,4'-bipy ligand, four carboxylate oxygen atoms from coordinated water molecules, while $\mathrm{Co} 2$ ion is coordinated by two nitrogen atoms from 4,4'-bipy ligand ligand, two carboxylate oxygen atoms from two different $\mathrm{H}_{2}$ btec $^{2-}$ ligands and two oxygen atoms from coordinated water molecules. As displayed in Figure 5, the 4,4'-bipy ligand in compound $\mathbf{3}$ also has two different modes: two pyridine rings in ligand 4,4'-bipy(A) are located in a plane, while another two pyridine rings of 4,4'-bipy(B) have a torsion angle. The $\mathrm{Co}-\mathrm{N}$ bond length falls in the range of 2.106(5)2.155(6) $\AA$, while the Co-O bond lengths vary from 2.075(4)-2.184(3) А.

In compound $3, \mathrm{Co} 1$ and $\mathrm{Co} 2$ ions are bridged by 4,4'-bipy(A) 4,4'-bipy(B) ligands, respectively, to form the one-dimensional Co-bipy chains. These 1D chains are further connected with each other to form a 2D network structure through the $\mu_{2}$-bridged $\mathrm{H}_{2}$ btec $^{2-}$ ligand (Figure 6). From the topological point of view, each Co atom can be defined as a 4-connected node, while the bridging $\mathrm{H}_{2}$ btec $^{2-}$ and 4,4'-bipy ligands can act as the edges. The network analysis reveals that the net of compound $\mathbf{3}$ also represents a $(4,4)$-connected sql topology (Figure 7).

\subsection{Thermogravimetric analysis}

Thermal properties of all three compounds were evaluated by thermogravimetric analysis from $25^{\circ} \mathrm{C}$ to $800^{\circ} \mathrm{C}$ under the nitrogen atmosphere with a heating rate of $10^{\circ} \mathrm{C} \cdot \min ^{-1}$. TGA measurements reveal that compound 3 is unstable in $\mathrm{N}_{2}$ atmosphere with the increase 

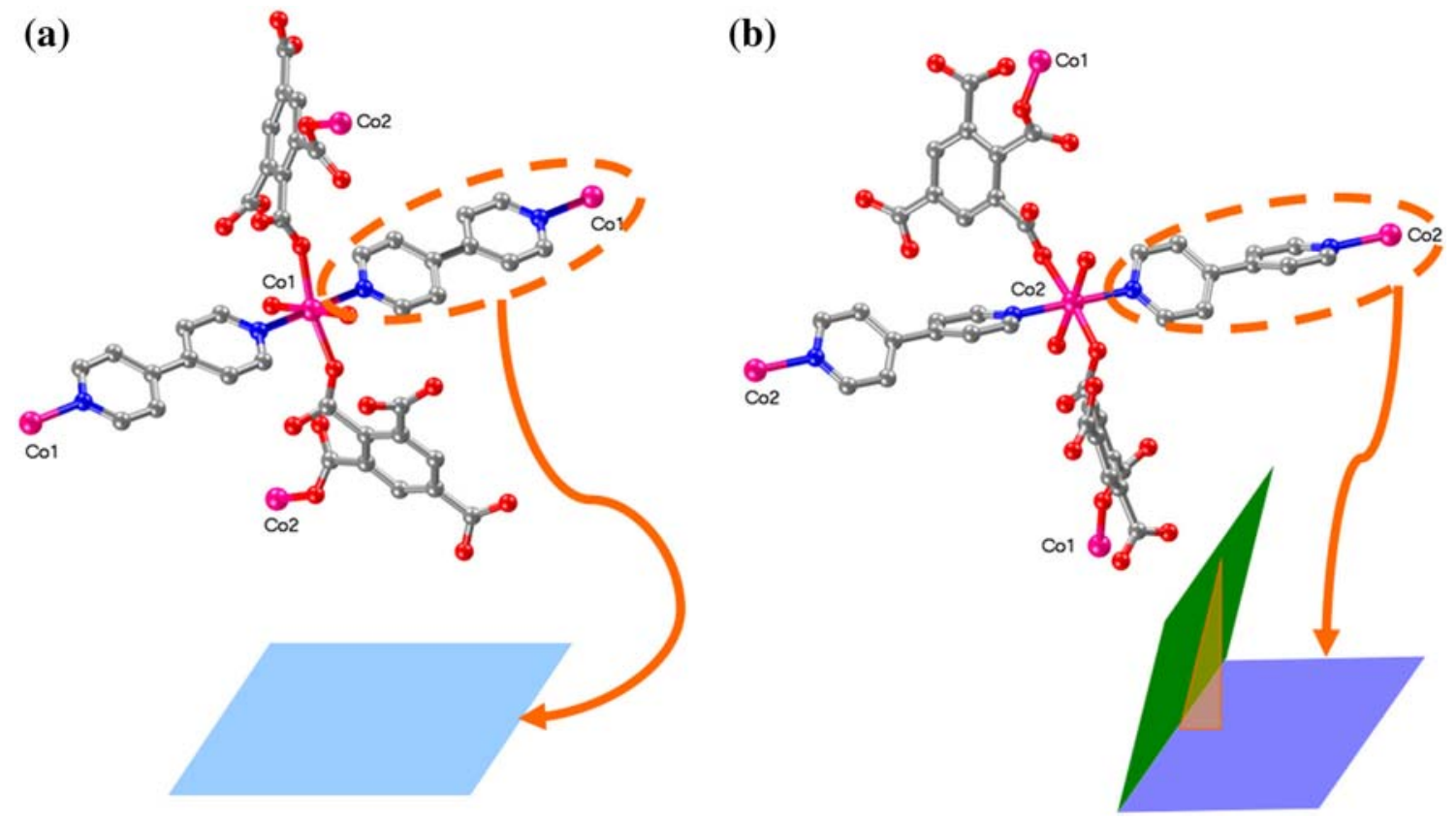

Figure 5. (a) Coordination environment of Co1 ion in compound 3. (b) Coordination environment of Co1 ion in compound $\mathbf{3}$. All hydrogen atoms are omitted for clarity.

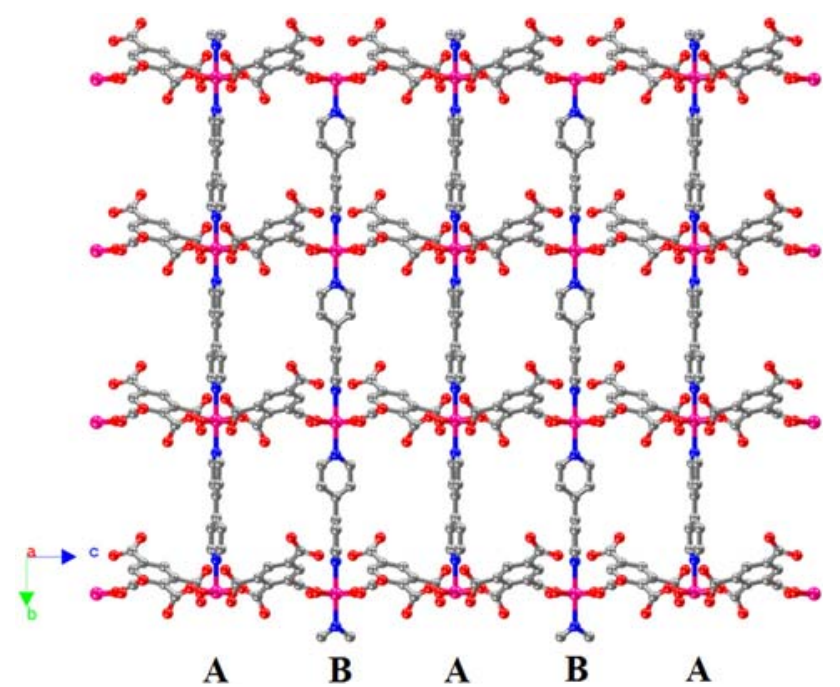

Figure 6. Packing structure of compound 3 ( $a$ axis).

in temperature. It is worth noting that the structures of compounds $\mathbf{1}$ and $\mathbf{2}$ begin to collapse after about $350^{\circ} \mathrm{C}$. As shown in the Figure 8. the first weight loss of compound $1(5.30 \%)$ occurs from 50 to $270^{\circ} \mathrm{C}$, corresponding to the loss of two water molecules per unit of $\left[\mathrm{Co}\left(\mathrm{H}_{3}\right.\right.$ btec $)$ (phen) $\left.\left(\mathrm{H}_{2} \mathrm{O}\right)_{2}\right][\mathrm{OH}] \cdot 3 \mathrm{H}_{2} \mathrm{O}$ (calcd.: $6.15 \%)$. The second weight loss of $5.91 \%$ appears from 270 to $400^{\circ} \mathrm{C}$, corresponding to the loss of two water molecules (calcd.: 6.15\%). After $400{ }^{\circ} \mathrm{C}$, the organic groups start to lose and the structure of compound $\mathbf{1}$ begins to decompose. As for compound 2, the first weight loss of $5.20 \%$ (calcd.: $5.06 \%$ ) is observed from

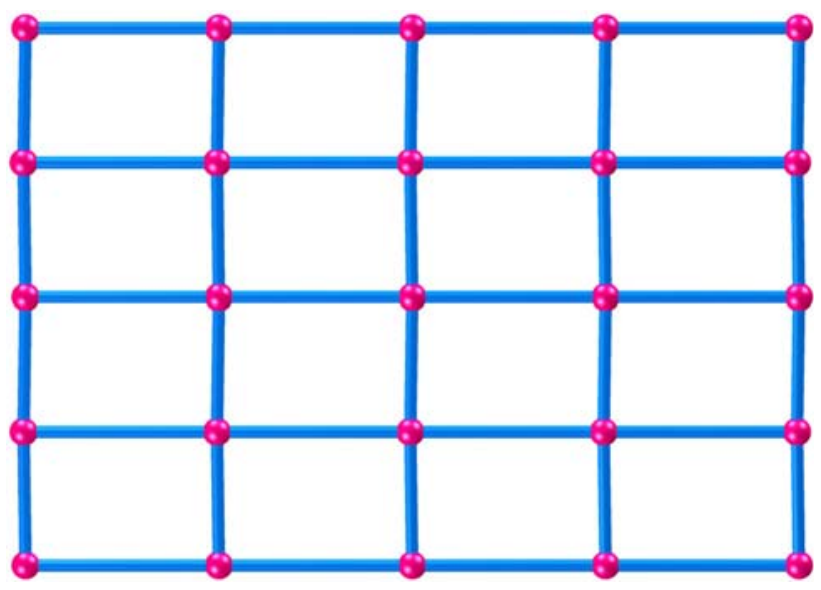

Figure 7. Topological structure of compound $\mathbf{3}$.

30 to $295^{\circ} \mathrm{C}$, which is in accordance with the loss of two water molecules. As the temperature increases, the 2D network structure of compound $\mathbf{2}$ begins to collapse after $355^{\circ} \mathrm{C}$. The first weight loss of $2.04 \%$ for compound 3 is observed from 30 to $175^{\circ} \mathrm{C}$, which is corresponding to one water molecule (calcd.: $2.09 \%$ ). After that, the organic groups start to lose and the structure of compound 3 begins to decompose.

\subsection{UV-Vis DRS analysis and photoluminescent properties}

The solid state UV-Vis DRS spectra show that the absorption peaks of compounds $\mathbf{1 - 3}$ are located at 259, 


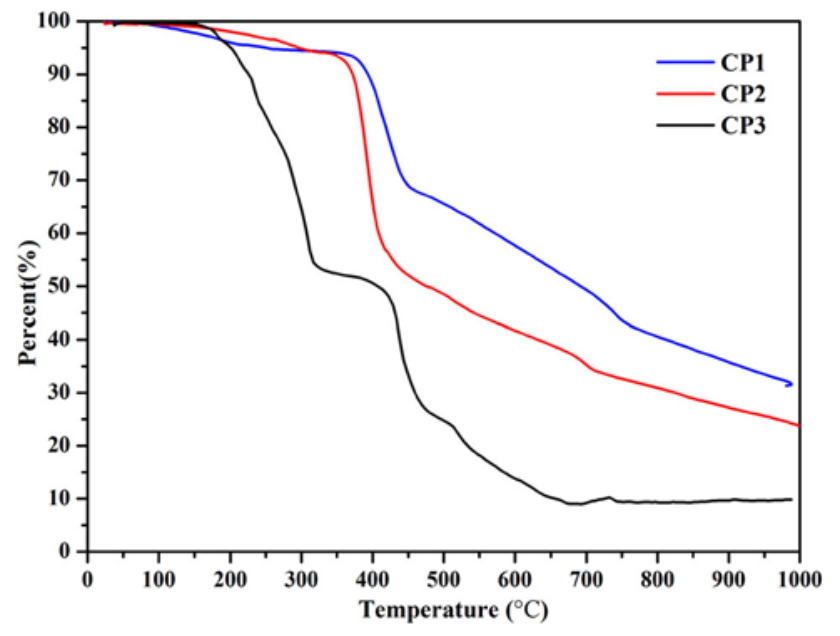

Figure 8. TGA curves of compounds compounds 1-3.

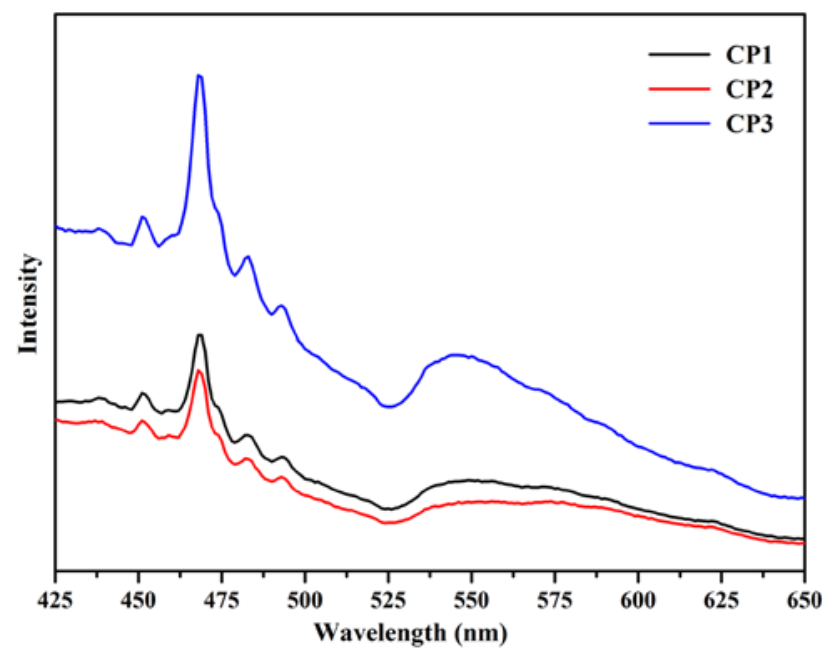

Figure 9. Emission spectra of compounds 1-3. $\lambda_{\mathrm{ex}}=$ $360 \mathrm{~nm}$.

287 and $250 \mathrm{~nm}$, respectively (Figure S9 in SI). Besides, there exists a broad absorption peak around $550 \mathrm{~nm}$ for compounds $\mathbf{1} \mathbf{- 3}$, which is attributed to the transition energy decrease of $\pi-\pi^{*}$ following the coordination bond formation between Co ion and electron-donating $\mathrm{N}$ atom. ${ }^{44}$

Coordination compounds with luminescent properties have attracted much attention due to their potential applications in the areas of chemical sensors and photochemistry. ${ }^{4,45,46}$ Therefore, the luminescent properties of compounds 1-3 were investigated in solid state at room temperature, and the emission spectra are shown in Figure 9. The weak emission of free ligand $\mathrm{H}_{4}$ btec in the energy range of $380-600 \mathrm{~nm}\left(\lambda_{\max }=394 \mathrm{~nm}\right)$ upon excitation at $354 \mathrm{~nm}$ might be attributed to a $\pi^{*}$ -n transition in the solid state, similar to those reported for free benzenecarboxylic acids. ${ }^{38}$ The solid state fluorescence spectra of compounds $\mathbf{1}-\mathbf{3}\left(\lambda_{\text {ex }}=360 \mathrm{~nm}\right)$ at room temperature show similar properties. As in Figure 9, the fluorescent emission peaks were observed at 459, 468 and $549 \mathrm{~nm}$ for $\mathbf{1}-\mathbf{3}$. The maximum emissions occur at $468 \mathrm{~nm}$, which are red-shifted by about $74 \mathrm{~nm}$ compared to that of the free $\mathrm{H}_{4}$ btec ligand ( $394 \mathrm{~nm}$ ) and may be attributed to a metal-to-ligand charge transfer (MLCT). ${ }^{47-49}$

\section{Conclusions}

In summary, three new coordination compounds based on multicarboxylate ligand $\mathrm{H}_{4}$ btec and $\mathrm{N}$-donor auxiliary ligands have been synthesized by hydrothermal method. X-ray crystallographic analysis shows that compound 1 possesses a 0D discrete structure, while compounds $\mathbf{2}$ and $\mathbf{3}$ exhibit 2D network structures, which exhibit a sql topology with the point symbol of $(4,4)$. Thermal analysis indicates that the main structures of compounds $\mathbf{1}$ and 2 begin to collapse after $350^{\circ} \mathrm{C}$. In addition, the photoluminescent properties of compounds 1-3 were also investigated in the solid state at room temperature.

\section{Supplementary Information (SI)}

CCDC 1511552, 1511553, and 1511554 contain the supplementary crystallographic data for the compounds 13. These data can be obtained free of charge via www. ccdc.cam.ac.uk/conts/retrieving.html, or from the Cambridge Crystallographic Data Centre, 12 Union Road, Cambridge CB2, 1EZ, UK; Fax: (+44) 1223-336-033, or by e-mail: deposit@ccdc.cam.ac.uk. Crystallographic data for coordination compounds 1-3 (Table S1), ORTEP drawings of compounds 1-3 (Figures S1, S4 and S5), Packing structure of compound 1 (Figure S2), Hydrogen-bonded supramolecular structure of 1 (Figure S3), solid state UV-Vis DRS spectra of compounds 1-3 (Figure S6) and cif/checkcif file are given in Supplementary Information. Supplementary Information is available at www.ias.ac.in/chemsci.

\section{Acknowledgements}

Financial support from the National Natural Science Foundation of China (Grants Nos. 51602130 and 21171075), the Natural Science Foundation of the Higher Education Institutions of Jiangsu Province (Grant No. 16KJD430002), and the Foundation of Jiangsu University (Grants Nos. 08JDG031 and 1283300004$)$ are gratefully acknowledged.

\section{References}

1. Kuang X F, Wu X Y, Yu R M, Donahue J P, Huang J S and Lu C Z 2010 Assembly of a metal-organic framework 
by sextuple intercatenation of discrete adamantane-like cages Nat. Chem. 2461

2. Meng M, Zhong D C and Lu T B 2011 Three porous metal-organic frameworks based on an azobenzenetricarboxylate ligand: synthesis, structures, and magnetic properties CrystEngComm 136794

3. Dawson R, Adams D J and Cooper A I 2011 Chemical tuning of $\mathrm{CO}_{2}$ sorption in robust nanoporous organic polymers Chem. Sci. 21173

4. Cui Y J, Yue Y F, Qian G D and Chen B L 2012 Luminescent Functional Metal-Organic Frameworks Chem. Rev. 1121126

5. Li J R, Sculley J and Zhou H C 2012 Metal-Organic Frameworks for Separations Chem. Rev. 112869

6. O'Keeffe M and Yaghi O M 2012 Deconstructing the crystal structures of metal-organic frameworks and related materials into their underlying nets Chem. Rev. 112675

7. Wang C, Zhang T and Lin W B 2012 Rational synthesis of noncentrosymmetric metal-organic frameworks for second-order nonlinear optics Chem. Rev. 1121084

8. Cohen S M 2012 Postsynthetic methods for the functionalization of metal-organic frameworks Chem. Rev. 112 970

9. Zhang J P, Zhang Y B, Lin J B and Chen X M 2012 Metal Azolate Frameworks: From Crystal Engineering to Functional Materials Chem. Rev. 1121001

10. Stock N and Biswas S 2012 Synthesis of metal-organic frameworks (MOFs): routes to various MOF topologies, morphologies, and composites Chem. Rev. 112933

11. Sugaya A, Ueno S, Okabayashi J and Kitazawa T 2014 Crystal structure and magnetic properties of the spin crossover complex $\mathrm{Fe}^{\mathrm{II}}$ (ethylnicotinate) $)_{2}\left[\mathrm{AuI}(\mathrm{CN})_{2}\right]_{2}$ New J. Chem. 381955

12. Risset $\mathrm{O} \mathrm{N}$, Quintero $\mathrm{P}$ A, Brinzari T V, Andrus M J, Lufaso M W, Meisel M W and Talham D R 2014 Light-Induced Changes in Magnetism in a Coordination Polymer Heterostructure, $\mathrm{Rb}_{0.24} \mathrm{Co}\left[\mathrm{Fe}(\mathrm{CN})_{6}\right]_{0.74}$ and the Role of the Shell Thickness on the Properties of Both Core and Shell J. Am. Chem. Soc. 136 15660

13. Dai J C, Wu X T, Fu Z Y, Cui C P, Hu S M, Du W X, Wu L M, Zhang H H and Sun R O 2002 Synthesis, Structure, and Fluorescence of the Novel Cadmium(II)Trimesate Coordination Polymers with Different Coordination Architectures Inorg. Chem. 411391

14. Livage C, Guillou N, Marrot J and Ferey G 2001 Construction of Two- and Three-Dimensional Coordination Polymers from Cobalt Trimesate Chem. Mater. 134387

15. Ko J W, Min K S and Suh M P 2002 A Hybrid Consisting of Coordination Polymer and Noncovalent Organic Networks: A Highly Ordered 2-D Phenol Network Assembled by Edge-to-Face $\pi-\pi$ Interactions Inorg. Chem. $\mathbf{4 1} 2151$

16. Paz F A A and Klinowski J 2003 Hydrothermal synthesis of a novel thermally stable three-dimensional ytterbiumorganic framework Chem. Commun. 1484

17. Kepert C J, Prior T J and Rosseinsky M J 2000 A Versatile Family of Interconvertible Microporous Chiral Molecular Frameworks: The First Example of Ligand Control of Network Chirality J. Am. Chem. Soc. 122 5158
18. Paz F A A and Klinowski J 2003 Novel cadmiumorganic frameworks with nitrilotriacetate J. Phys. Org. Chem. 16772

19. Nangia A 2010 Supramolecular chemistry and crystal engineering J. Chem. Sci. 122295

20. Lin H Y, Sun J J, Liu G C, Wang X and Chen P W 2017 Self-assembly, structures and properties of three new Ni(II) coordination polymers derived from two different bis-pyridyl-bis-amide ligands and two aromatic polycarboxylates J. Chem. Sci. 1299

21. Ganesan S V and Natarajan S A 2004 lanthanum pyromellitate coordination polymer with threedimensional structure J. Chem. Sci. 11665

22. Murugavel R, Anantharaman G, Krishnamurthy D, Sathiyendiran M and Walawalkar M G 2000 Extended metal-organic solids based on benzenepolycarboxylic and aminobenzoic acids J. Chem. Sci. 112273

23. Paz F A A and Klinowski J 2004 Synthesis and Characterization of a Novel Cadmium-Organic Framework with Trimesic Acid and 1,2-Bis(4-pyridyl)ethane Inorg. Chem. 433948

24. MacLeod J M, Lipton-Duffin J A, Cui D, De Feyter S and Rosei F 2015 Substrate Effects in the Supramolecular Assembly of 1,3,5-Benzene Tricarboxylic Acid on Graphite and Graphene Langmuir 317016

25. Liu K, You $\mathrm{H}$ P, Jia $G$, Zheng $Y \mathrm{H}$, Song $\mathrm{Y} \mathrm{H}$, Yang M, HuangY J and Zhang H J 2009 CoordinationInduced Formation of One-Dimensional Nanostructures of Europium Benzene-1,3,5-tricarboxylate and Its SolidState Thermal Transformation Cryst. Growth Des. 9 3519

26. Neufeld M J, Harding J L and Reynolds M M 2015 Immobilization of Metal-Organic Framework Copper(II) Benzene-1,3,5-tricarboxylate (CuBTC) onto Cotton Fabric as a Nitric Oxide Release Catalyst ACS Appl. Mater. Interfaces 726742

27. Vakiti R K, Garabato B D, Schieber N P, Rucks M J, Cao Y, Webb C, Maddox J B, Celestian A, Pan W P and Yan B B 2012 Synthesis and Characterization of Two- and Three-Dimensional Calcium Coordination Polymers Built with Benzene-1,3,5-tricarboxylate and/or Pyrazine-2-carboxylate Cryst. Growth Des. 12 3937

28. Šimėnas M, Ibenskas A and Tornau E E 2015 Coronene Molecules in Hexagonal Pores of Tricarboxylic Acids: A Monte Carlo Study J. Phys. Chem. C 11920524

29. Thuéry P and Harrowfield J 2014 Uranyl Ion Complexes with all-cis-1,3,5-Cyclohexanetricarboxylate: Unexpected Framework and Nanotubular Assemblies Cryst. Growth Des. 144214

30. Li C, Lou X B, Shen M, Hu X S, Guo Z, Wang Y, Hu B W and Chen Q 2016 High Anodic Performance of Co 1,3,5-Benzenetricarboxylate Coordination Polymers for Li-Ion Battery ACS Appl. Mater. Interfaces 815352

31. Xu L, Kwon Y U and de Castro B Novel Mn(II)-Based Metal-Organic Frameworks Isolated in Ionic Liquids 2013 Cryst. Growth Des. 131260

32. Jia H P, Li W, Ju Z F and Zhang J $2007\left[\mathrm{Co}_{5}\left(\mu_{3}-\mathrm{OH}\right)_{2}\right.$ $\left.(\mathrm{btec})_{2}(\mathrm{bpp})\right]_{\mathrm{n}}$ : a three-dimensional homometallic molecular metamagnet built from the mixed hydroxide/ carboxylate-bridged ferrimagnetic-like chains Dalton Trans. 3699 
33. Murugavel R, Krishnamurthy D and Sathiyendiran M 2002 Anionic metal-organic and cationic organic layer alternation in the coordination polymers $\left[\left\{\mathrm{M}(\mathrm{BTEC})\left(\mathrm{OH}_{2}\right)_{4}\right\} \cdot\left\{\mathrm{C}_{4} \mathrm{H}_{12} \mathrm{~N}_{2}\right\} \cdot 4 \mathrm{H}_{2} \mathrm{O}\right]_{\mathrm{n}}(\mathrm{M}=\mathrm{Co}$, $\mathrm{Ni}$, and $\mathrm{Zn} ; \mathrm{BTEC}=1,2,4,5$-benzenetetracarboxylate) $\mathrm{J}$. Chem. Soc., Dalton Trans. 34

34. Song P, Liu B, Li Y Q, Yang J Z, Wang Z M and Li X G 2012 Two pillared-layer metal-organic frameworks constructed with $\mathrm{Co}(\mathrm{II}), 1,2,4,5$-benzenetetracarboxylate, and 4,4'-bipyridine: syntheses, crystal structures, and gas adsorption properties CrystEngComm 142296

35. Zhong D C, Lu W G and Deng J H 2014 Two three-dimensional cadmium(II) coordination polymers based on 5-amino-tetrazolate and 1,2,4,5-benzenetetracarboxylate: the $\mathrm{pH}$ value controlled syntheses, crystal structures and luminescent properties CrystEngComm 164633

36. Xia C K, Wu F, Yang K, Sun W, Min Y Y, Wu Y L and Lu X J 2016 Zn(II) and Cd(II) complexes assembled from versatile 1,2,3,5-benzenetetracarboxylic acid and chelating N-donor auxiliary coligands Polyhedron 117 637

37. Xia C K, Wu F, Yang K, Wu Y L and Lu X J 2016 Syntheses, crystal structures and properties of four novel zinc(II) complexes assembled from versatile 1,2,3,5benzenetetracarboxylic acid and bridging dipyridyl ligands Polyhedron 11278

38. Wei C, Xia C K, Wu Y L, Wu F, Yang S and Ma J L 2015 Syntheses, crystal structures and properties of four novel coordination polymers assembled from versatile 1,2,3,5-benzenetetracarboxylic acid Polyhedron 89189

39. Sheldrick G M, 1997, SADABS, Program for Empirical Absorption Correction of Area Detector Data, University of Gottingen, Gottingen, Germany

40. Sheldrick G M 1997, SHELXS-97, Program for Crystal Structure Solution, University of Gottingen, Gottingen, Germany
41. Gagnon K J, Perry H P and Clearfield A 2012 Conventional and Unconventional Metal-Organic Frameworks Based on Phosphonate Ligands: MOFs and UMOFs Chem. Rev. 1121034

42. Zhou J, Liu Q, Feng W, Sun Y and Li F Y 2015 Upconversion Luminescent Materials: Advances and Applications Chem. Rev. 115395

43. He C B, Liu D M and Lin W B 2015 Nanomedicine Applications of Hybrid Nanomaterials Built from MetalLigand Coordination Bonds: Nanoscale Metal-Organic Frameworks and Nanoscale Coordination Polymers Chem. Rev. 11511079

44. Cui Y, Yue Y and Qian G 2012 Luminescent Functional Metal-Organic Frameworks Chem. Rev. 112 1126

45. Hu Z C, Deibert B J and Li J 2014 Luminescent metalorganic frameworks for chemical sensing and explosive detection Chem. Soc. Rev. 435815

46. He Y P, Tan Y X and Zhang J 2014 Guest inducing fluorescence switching in lanthanide-tris((4carboxyl)phenylduryl)amine frameworks integrating porosity and flexibility J. Mater. Chem. C 2 4436

47. Kim T H, Shin Y W, Jung J H, Kim J S and Kim J 2008 Crystal-to-Crystal Transformation between Three CuI Coordination Polymers and Structural Evidence for Luminescence Thermochromism Angew. Chem. Int. Ed. 47685

48. da Silva S A, Leite C Q F, Pavan F R, Masciocchi N and Cuin A 2014 Coordinative versatility of a Schiff base containing thiophene: Synthesis, characterization and biological activity of zinc(II) and silver(I) complexes Polyhedron 79170

49. Naik S, Mague J T and Balakrishna M S 2014 Short-Bite PNP Ligand-Supported Rare Tetranuclear $\left[\mathrm{Cu}_{4} \mathrm{I}_{4}\right]$ Clusters: Structural and Photoluminescence Studies Inorg. Chem. 533864 